OPEN ACCESS

Edited by:

Lin Zhang,

Hubei University of Chinese Medicine,

China

Reviewed by:

Zhu Wanlong,

Yunnan Normal University, China

Shigui Wang,

Hangzhou Normal University, China

${ }^{*}$ Correspondence:

Le Kang

Ikang@ioz.ac.cn

Specialty section:

This article was submitted to

Ecophysiology,

a section of the journal

Frontiers in Ecology and Evolution

Received: 20 June 2021

Accepted: 26 August 2021

Published: 17 September 2021

Citation:

Wu T, Hao S and Kang L (2021)

Effects of Soil Temperature and Moisture on the Development and Survival of Grasshopper Eggs

in Inner Mongolian Grasslands.

Front. Ecol. Evol. 9:727911.

doi: 10.3389/fevo.2021.727911

\section{Effects of Soil Temperature and Moisture on the Development and Survival of Grasshopper Eggs in Inner Mongolian Grasslands}

\author{
Tingjuan Wu ${ }^{1,2}$, Shuguang $\mathrm{Hao}^{1}$ and Le Kang ${ }^{1 *}$ \\ ${ }^{1}$ State Key Laboratory of Integrated Management of Insect Pests and Rodents, Institute of Zoology, Chinese Academy \\ of Sciences, Beijing, China, ${ }^{2}$ College of Pharmacy, Henan University of Chinese Medicine, Zhengzhou, China
}

Grasshopper eggs overwinter in soil for almost half a year. Changes in soil temperature and moisture have a substantial effect on grasshopper eggs, especially temperature and moisture extremes. However, the combinatorial effect of temperature and moisture on the development and survival of grasshopper eggs has not been well studied. Here, we examined the effects of different soil moistures $\left(2,5,8,11,14 \%\right.$ water content) at $26^{\circ} \mathrm{C}$ and combinations of extreme soil moisture and soil temperature on the egg development and survival of three dominant species of grasshopper (Dasyhippus barbipes, Oedaleus asiaticus, and Chorthippus fallax) in Inner Mongolian grasslands. Our data indicated that the egg water content of the three grasshopper species was positively correlated with soil moisture but negatively correlated with hatching time. The relationship between hatching rate and soil moisture was unimodal. Averaged across 2 and $11 \%$ soil moisture, a soil temperature of $35^{\circ} \mathrm{Csignificantly} \mathrm{advanced} \mathrm{the} \mathrm{egg} \mathrm{hatching} \mathrm{time} \mathrm{of} D$. barbipes, $O$. asiaticus, and $C$. fallax by $5.63,4.75$, and 2.63 days and reduced the egg hatching rate of $D$. barbipes by $18 \%$. Averaged across 26 and $35^{\circ} \mathrm{C}, 2 \%$ soil moisture significantly delayed the egg hatching time of $D$. barbipes, $O$. asiaticus, and $C$. fallax by $0.69,11.01$, and 0.31 days, respectively, and decreased the egg hatching rate of $D$. barbipes by $10 \%$. The hatching time was prolonged as drought exposure duration increased, and the egg hatching rate was negatively correlated with drought exposure duration, except for $O$. asiaticus. Overall, the combination of high soil temperature and low soil moisture had a significantly negative effect on egg development, survival, and egg hatching. Generally, the response of grasshopper eggs to soil temperature and moisture provides important information on the population dynamics of grasshoppers and their ability to respond to future climate change.

Keywords: climate change, embryonic development, grasshopper, soil moisture, soil temperature

\section{INTRODUCTION}

Experiments and models have indicated that climate change has significant effects on the population dynamics, phenology and distribution of insects (Walther et al., 2002; Parmesan and Yohe, 2003; Root et al., 2003; Parmesan, 2006; Poniatowski et al., 2020). For example, experimental warming and precipitation interactively modulate the mortality rate and timing of 
spring emergence of a gallmaking tephritid fly (Xi et al., 2016). Warmer and drier weather in the preceding year increase the winter mortality of honey bees (Switanek et al., 2016). In recent decades, the frequency of extreme weather events (e.g., drought and high temperature) has increased (Deutsch et al., 2008), and these events have affected the development and survival of insects (Katz and Brown, 1992; Bale et al., 2002; Jentsch et al., 2009; Allen et al., 2010). Although many studies have focused on the effects of average variation in climatic factors on the development and survival of insects (Masters et al., 1998; Frampton et al., 2000; Srygley, 2014; Gherlenda et al., 2016), the responses of insects to extreme environments remain unclear. An improved understanding of the effects of extreme environments on insects may greatly enhance our knowledge of how climate change affects the distribution, phenology and population dynamics of insects.

Grasshoppers are important primary consumers in temperate grassland ecosystems. Female grasshoppers lay their eggs in the soil and endure a severe season (hot and dry summer or cold and wet winter). Thus, the egg stage is the most crucial developmental period for grasshoppers, as it determines their abundance in the following year. The embryonic development, survival, and hatching time of grasshopper eggs largely depend on soil temperature and moisture (Mukerji and Gage, 1978; Wagner et al., 1984; Honek and Kocourek, 1990; Briere et al., 1999; Hao and Kang, 2004a,b; Walter et al., 2018). Furthermore, grasshopper life cycles vary with elevation (Dingle and Mousseau, 1994; Telfer and Hassall, 1999), latitude (Groeters and Shaw, 1992), topography (Coxwell and Bock, 1995), and soil type (Poniatowski et al., 2020), all of which are associated with variation in soil temperature and moisture. Grasshopper population outbreaks are closely associated with environmental conditions, such as flooding, drought, or warm winters experienced during the egg stage (Powell et al., 2007; Yu et al., 2009; Zhang et al., 2009). Grasshopper species vary in the strategies they employ to adapt to unpredictable changes in environmental factors. For example, grasshoppers have evolved different embryonic diapause traits (facultative, obligate, or no diapause) (Hao and Kang, 2004a; Guo et al., 2009) to alter egg hatching time based on environmental conditions. Thus, studying the responses of grasshopper egg development and survival to soil temperature and moisture may provide valuable insights into the ecological mechanisms underlying the adaptation of grasshoppers to environmental changes.

The Inner Mongolian grasslands are located in arid and semiarid regions, where organisms often face year-round drought stress. However, severe drought and high temperature tend to be more common in late spring and summer. Precipitation is typically concentrated in the fall. In Inner Mongolian grasslands, the dominant grasshopper species Dasyhippus barbipes, Oedaleus asiaticus, and Chorthippus fallax can generally be divided into early-, mid- and late-season species, respectively, based on their phenology. These grasshopper species have divergent life history traits and occupy distinct spatial and temporal ecological niches (Kang and Chen, 1994a). Our previous studies have shown that these grasshopper species respond differently to temperature and moisture treatments in laboratory experiments (Hao and Kang, 2004a,b; Zhao et al., 2005; Kang et al., 2007). The early-season species $D$. barbipes has obligate diapause, and warming does not significantly advance its egg hatching time. In contrast, warming advances the egg hatching time of the late-season species C. fallax, which does not have diapause (Guo et al., 2009). These studies suggest that diapause traits of grasshopper species can buffer them from the effects of environmental change (Guo et al., 2009; Wu et al., 2012; Kearney et al., 2018) or increase the sensitivity of embryonic development to environmental change. In addition, insect hatching in spring may be more strongly affected by environmental forces compared with the later hatching of other species (Walter et al., 2018). Therefore, study of the responses of different grasshopper species to soil temperature and moisture can improve our ability to predict how their distribution will change in response to climate change.

In this study, we examined three dominant species of grasshoppers that vary in their phenology and habitat use. $D$. barbipes and $O$. asiaticus are early- and mid-season species, respectively, that prefer xeriphilic environments. C. fallax is a late-season species that prefers humid environments. We carried out a series of individual and cross over experiments of soil temperatures and moisture to investigate their combinatorial effect on the embryonic development and survival of grasshopper eggs under laboratory conditions. The aim was to test the hypotheses that the effects of soil temperature and moisture on grasshopper egg development and survival are species-specific and that late-season grasshopper species are more sensitive to lower soil temperature and moisture than early- and mid-season grasshopper species.

\section{MATERIALS AND METHODS}

\section{Egg Collection}

We obtained eggs of three grasshopper species, D. barbipes, $O$. asiaticus and C. fallax, by collecting adult grasshoppers in the grasslands of Duo Lun County $\left(42^{\circ} 02^{\prime} \mathrm{N}, 116^{\circ} 17^{\prime} \mathrm{E}, 1324 \mathrm{~m}\right.$ a.s.l.) of Inner Mongolia, China. In this region, the long-term (19532007) mean annual air temperature is $2.1^{\circ} \mathrm{C}$, and the monthly mean temperature ranges from $18.9^{\circ} \mathrm{C}$ in July to $-17.5^{\circ} \mathrm{C}$ in January. The mean annual precipitation is $383 \mathrm{~mm}$, with $90 \%$ falling between May and October.

Field-collected adult grasshoppers were reared in cages in the laboratory to produce egg pods under a 14:10 (light:dark) photoperiod. 60-W tungsten filament bulbs were used to provide light from 8:00 a.m. to 10:00 p.m. and $26^{\circ} \mathrm{C}$ air temperatures in daytime for adult rearing cages. We fed the grasshoppers fresh gramineous plants collected from the field daily. To collect eggs, we placed a plastic pot filled with moistened sand on the bottom of the cage so that adult females could lay eggs. The egg pods were then sieved out from the pot every 2 days. We transferred these egg pods to a small plastic cup filled with sterile sand containing $5 \%$ water content by mass. We kept these cups in a $5^{\circ} \mathrm{C}$ refrigerator before using them in the manipulative experiments.

\section{Experimental Substrate and Preparation}

The experimental substrate was sand, which was sifted through a $2-\mathrm{mm}^{2}$ sieve, washed with water to clean out the clay, oven-dried 
at $180^{\circ} \mathrm{C}$ for $12 \mathrm{~h}$ for sterilization, and then moistened to 2,5 , 8,11 , and $14 \%$ of the water content by gross mass. To ensure that egg pods had the same water content at the start of the experiment, we placed all egg pods in soil with 5\% moisture and at $18^{\circ} \mathrm{C}$ for 3 days prior to starting the experiment. Twenty egg pods of each grasshopper species were randomly selected and placed in a plastic cup (inner diameter $7.5 \mathrm{~cm}$ and height $8.5 \mathrm{~cm}$, holds about $250 \mathrm{~g}$ dry sand) filled with sand with different moisture levels. Each cup was a replicate of each treatment, which consisted of two temperatures and 6 levels of moisture. We sealed the cups with parafilm and replaced sand weekly to maintain constant soil moisture.

\section{Effect of Soil Moisture on the Egg Water Content}

To measure the effects of soil moisture on the egg water content of each grasshopper species, we placed the cups with egg pods and different soil moistures (described above) into an incubator at $18^{\circ} \mathrm{C}$ (to slow the embryonic growth rate to minimize the effect of embryonic development on the egg water content) for 5 days. We weighed the wet mass of egg pods, oven-dried the egg pods at $65^{\circ} \mathrm{C}$ for $72 \mathrm{~h}$, and reweighed the egg pods for dry mass to calculate the egg water content with a precision of $+/-0.01 \mathrm{mg}$. All treatments had 6 replicates.

\section{Main Effects of Soil Moisture on Egg Hatching Time and Survival}

To measure the effect of soil moisture on hatching time and survival, we incubated the cups with egg pods at moistened with $2,5,8,11$ and $14 \%$ and at $26^{\circ} \mathrm{C}$ (the favorable temperature for grasshopper egg development). The egg pods were examined daily to record the number of hatchlings and the number of dead grasshopper eggs in each treatment. After 60 days, we considered any remaining eggs to have entered diapause. We incubated these eggs in diapause at $4^{\circ} \mathrm{C}$ for 60 days to break diapause and then moved them to $26^{\circ} \mathrm{C}$. We kept all treatments at $26^{\circ} \mathrm{C}$ for another 60 days in post-diapause development and recorded the number of hatchlings daily. At the end of the experiment, all egg pods were dissected to examine the number of living eggs. All treatments had 6 replicates.

\section{Interactive Effects of Soil Temperature and Moisture on Egg Hatching Time and Survival}

We used 2 and $11 \%$ as the lowest and highest soil moisture based effect of soil moisture on egg water content, and $26^{\circ} \mathrm{C}$ and $35^{\circ} \mathrm{C}$ as normal and high soil temperatures based on local field meteorological data ( $\mathrm{Wu}$ et al., 2012) to form four cross treatments $\left(11 \%\right.$ and $35^{\circ} \mathrm{C}, 11 \%$ and $26^{\circ} \mathrm{C}, 2 \%$ and $35^{\circ} \mathrm{C}, 2 \%$ and $26^{\circ} \mathrm{C}$ ), respectively. First, we incubated plastic cups with twenty egg pods of each grasshopper species and silver sand of 2 and $11 \%$ moisture at $26^{\circ} \mathrm{C}$ for 60 days to confirm that all eggs had entered diapause. Second, we incubated all cups at $4^{\circ} \mathrm{C}$ for 60 days to terminate egg diapause. Finally, we incubated cups at either $26^{\circ} \mathrm{C}$ or $35^{\circ} \mathrm{C}$, resulting in four cross treatments of temperature and moisture. We recorded the number of hatched eggs and deaths from all treatments daily for 60 days. Because C. fallax is a non-diapause species, we skipped the incubation at $26^{\circ} \mathrm{C}$ for prediapause development and $4^{\circ} \mathrm{C}$ for diapause termination and directly placed C. fallax eggs into the four cross treatments of temperature and soil moisture. At the end of the experiment, we dissected all the egg pods and recorded the number of unhatched eggs alive or dead. All treatments had 6 replicates.

\section{Effect of Embryonic Stage and Drought Duration on Egg Hatching Time and Survival}

To determine the embryonic stage during which eggs are most sensitive to drought and how drought exposure duration affects the hatching time and hatching rate of the three grasshopper species, we designed experiments in which the embryonic stage (eggs with prediapause development for 5 and 15 days before we initiated drought treatment) and drought exposure duration varied. We took grasshopper eggs that had developed for 5 and 15 days at $26^{\circ} \mathrm{C}$ and $8 \%$ sand moisture. Eggs were then transferred to cups filled with anhydrous sand ( $0 \%$ moisture) for $0,5,10$, 15 , or 20 days at $26^{\circ} \mathrm{C}$. Afterward, we returned the eggs to $8 \%$ soil moisture conditions for 60 days and continually incubated unhatched eggs at $4^{\circ} \mathrm{C}$ for 60 days to terminate diapause. We finally incubated postdiapause eggs at $26^{\circ} \mathrm{C}$ and $8 \%$ moisture for another 60 days. We recorded the number of hatchlings and dead eggs during pre- and postdiapause development daily. We dissected egg pods and recorded the number of live and dead eggs at the end of the experiment. All treatments had 6 replicates.

Generally, egg development at 5 and 15 days under normal conditions is associated with the embryonic stages of prediapause (stages 10-11 and stages 16-17, respectively). In this experiment, we defined a standard variation index (VI) to compare the sensitivity of the response of egg hatching time and hatching rate to drought exposure duration among the different grasshopper species. VI = (egg hatching time (or hatching rate) of drought treatment-egg hatching time (or hatching rate) of control treatment)/egg hatching time of control treatment. Higher values indicate greater sensitivity of the hatching time or hatching rate of grasshopper eggs to drought exposure duration.

\section{Data Analysis}

We used three- and two-way ANOVAs to examine the main and interactive effects of species, soil moisture, soil temperature, embryonic development stage, and drought duration on egg hatching time and hatching rate of the three grasshopper species. We performed one-way ANOVAs to assess variation in egg water content, egg hatching time and hatching rate among different soil moisture levels for each grasshopper species. We used linear regressions and polynomial analyses to measure the relationships between soil moisture and egg water content as well as between egg hatching time and hatching rate for each grasshopper species. The slopes of the regression models were used to compare the sensitivity of the three grasshopper species to changes in soil moisture. We followed ANOVAs with post hoc analyses (Duncan test; alpha $=0.05$ ) to assess differences among soil moisture levels. In this study, we referred 
to hatching time as the duration required for $50 \%$ of eggs to hatch in each treatment and the hatching rate as the number of eggs hatched at the end of each trial/the number of eggs at the beginning of each trial. We conducted all statistical analyses using SPSS 16.0 software (SPSS Inc., Chicago, Illinois, United States).

\section{RESULTS}

\section{Effect of Soil Moisture on Grasshopper Egg Water Content, Hatching Time and Hatching Rate}

Before treatments, the egg water content of the mid-season species, O. asiaticus (39.65\%), and late-season species, C. fallax (38.43\%), was much higher compared with the early-season species, D. barbipes (30.86\%). When incubated at $18^{\circ} \mathrm{C}$ for 5 days, the egg water content differed among grasshopper species prior to any manipulative experiments $\left[F_{(2,60)}=145.26, P<0.01\right]$. The egg water content of the three grasshopper species was positively correlated with soil moisture (Figures $\mathbf{1 A}-\mathbf{C}$ ), but the response was stronger in the xeriphilic species $D$. barbipes and $O$. asiaticus than in the mesic species C. fallax. ANOVA indicated that soil moisture levels significantly affected the egg water content of D. barbipes $\left[F_{(4,20)}=46.91, P<0.01\right.$; Figure 1A $]$ and $O$. asiaticus $\left[F_{(4,20)}=9.96, P<0.01\right.$; Figure 1B $]$. Soil moisture only had a marginally significant effect on the egg water content of $C$. fallax. The egg water content was only markedly decreased under $2 \%$ soil moisture compared with eggs at other soil moisture levels $\left[F_{(4,20)}=2.83, P=0.05\right.$; Figure 1C $]$.

At the five levels of soil moisture at $26^{\circ} \mathrm{C}$, there were significant differences in egg hatching time $\left[F_{(2,75)}=713.57, P<0.01\right.$; Figures 1D-F] among the three grasshopper species. The eggs of the mid-season species $O$. asiaticus required a longer period to reach $50 \%$ hatching ( 24.38 days) compared with the eggs of the late-season species C. fallax (14.94 days) and early-season species $D$. barbipes (12.50 days). The egg hatching time of the three grasshopper species was significantly negatively correlated with soil moisture (Figures 1D-F). The egg hatching times of $D$. barbipes and $O$. asiaticus were more sensitive to soil moisture than those of $C$. fallax. The egg hatching times of D. barbipes $\left[F_{(4,25)}=64.83, P<0.1\right.$; Figure 1D] and $O$. asiaticus $\left[F_{(4,25)}=7.01, P<0.1\right.$; Figure $\left.1 \mathrm{E}\right]$ in the $2 \%$ soil moisture treatment were significantly longer than those in the other soil moisture treatments. In contrast, there was no difference in egg hatching time among moisture levels for C. fallax $\left[F_{(4,25)}=1.39\right.$, $P=0.27$; Figure 1F].

There were significant differences in egg hatching rate $\left[F_{(2,75)}=567.69, P<0.01 ;\right.$ Figures 1G-I $]$ among the three grasshopper species. The egg hatching rate of C. fallax $(79.47 \%)$ was significantly higher than that of D. barbipes $(35.80 \%)$ and O. asiaticus (12.50\%) Regardless of grasshopper species, the relationships between egg hatching rate and soil moisture were unimodal, and the highest egg hatching rates were observed at 8 and 11\% soil moisture (Figures 1G-I). The egg hatching rates of D. barbipes at 5,8 , and $11 \%$ soil moisture were significantly higher than those at the two extreme soil moisture levels (2 and $14 \%)\left[F_{(4,25)}=10.24, P<0.01\right.$; Figure 1G]. The egg hatching rate of $O$. asiaticus was higher at $11 \%$ soil moisture than at other soil moisture levels $\left[F_{(4,25)}=3.17, P=0.03\right.$; Figure $\left.\mathbf{1 H}\right]$. The egg hatching rate of $C$. fallax was not significantly affected by soil moisture $\left[F_{(4,25)}=0.51, P=0.73\right.$; Figure 1I]. In general, 8 and $11 \%$ soil water content at $26^{\circ} \mathrm{C}$ resulted in the shortest hatching time and the highest hatching rates regardless of species.

\section{Interactive Effects of Soil Temperature and Moisture on the Egg Hatching Time and Rate}

Averaged across the two soil moisture treatments, the higher temperature $\left(35^{\circ} \mathrm{C}\right)$ significantly shortened the egg hatching time and reduced the hatching rate of the three grasshopper species compared with the treatments at $26^{\circ} \mathrm{C}$ (all $P<0.01$; Table 1 and Figures 2A-C). Averaged across the two soil temperatures and three grasshopper species, $2 \%$ soil moisture prolonged the egg hatching time and decreased the hatching rate compared with $11 \%$ soil moisture (all $P<0.01$; Table 1 and Figures 2A-C). There were no interactive effects of soil temperature and moisture on the egg hatching time and hatching rate of the three grasshopper species. Furthermore, there were interactive effects between soil temperature and grasshopper species and between soil moisture and grasshopper species on the hatching time and hatching rate of the three grasshopper species (all $P<0.01$; Table 1). Thus, grasshopper species significantly differed in their responses to soil temperature and moisture combinations.

Soil temperature and moisture have significant effects on the egg hatching time and hatching rate of each grasshopper species. Averaged across the two soil moistures, $35^{\circ} \mathrm{C}$ soil temperature significantly shortened the hatching time of $D$. barbipes, $O$. asiaticus and C. fallax by 5.63, 4.75, and 2.73 days, respectively (all $P<0.05$ ). However, the soil temperature at $35^{\circ} \mathrm{C}$ significantly reduced the egg hatching rate of $D$. barbipes by $18 \%$ comparedwiththat at $26^{\circ} \mathrm{C}$. Averaged across the two soil temperatures, $2 \%$ soil moisture increased the hatching time of D. barbipes, O. asiaticus and C. fallax by $0.69,11.01$, and 0.31 days, respectively (all $P<0.05$ ). The soil moisture at $2 \%$ reduced the egg hatching rate of $D$. barbipes by $10 \%$ compared with that under $11 \%$ soil moisture $(P<0.01$; Figure $2 D)$. No interactive effects of soil temperature and moisture on the egg hatching time and hatching rate of the three grasshopper species were detected (Table 1 and Figures 2E,F).

\section{Effects of Embryonic Developmental Stage and Drought Duration on Egg Hatching Time and Hatching Rate}

A standard VI was used to compare the response sensitivity of egg hatching time and hatching rate to drought exposure duration between different grasshopper species. Averaged over the three grasshopper species, embryonic stage had no effect on the response of VI of hatching time to drought exposure duration. The hatching time was prolonged with increasing 

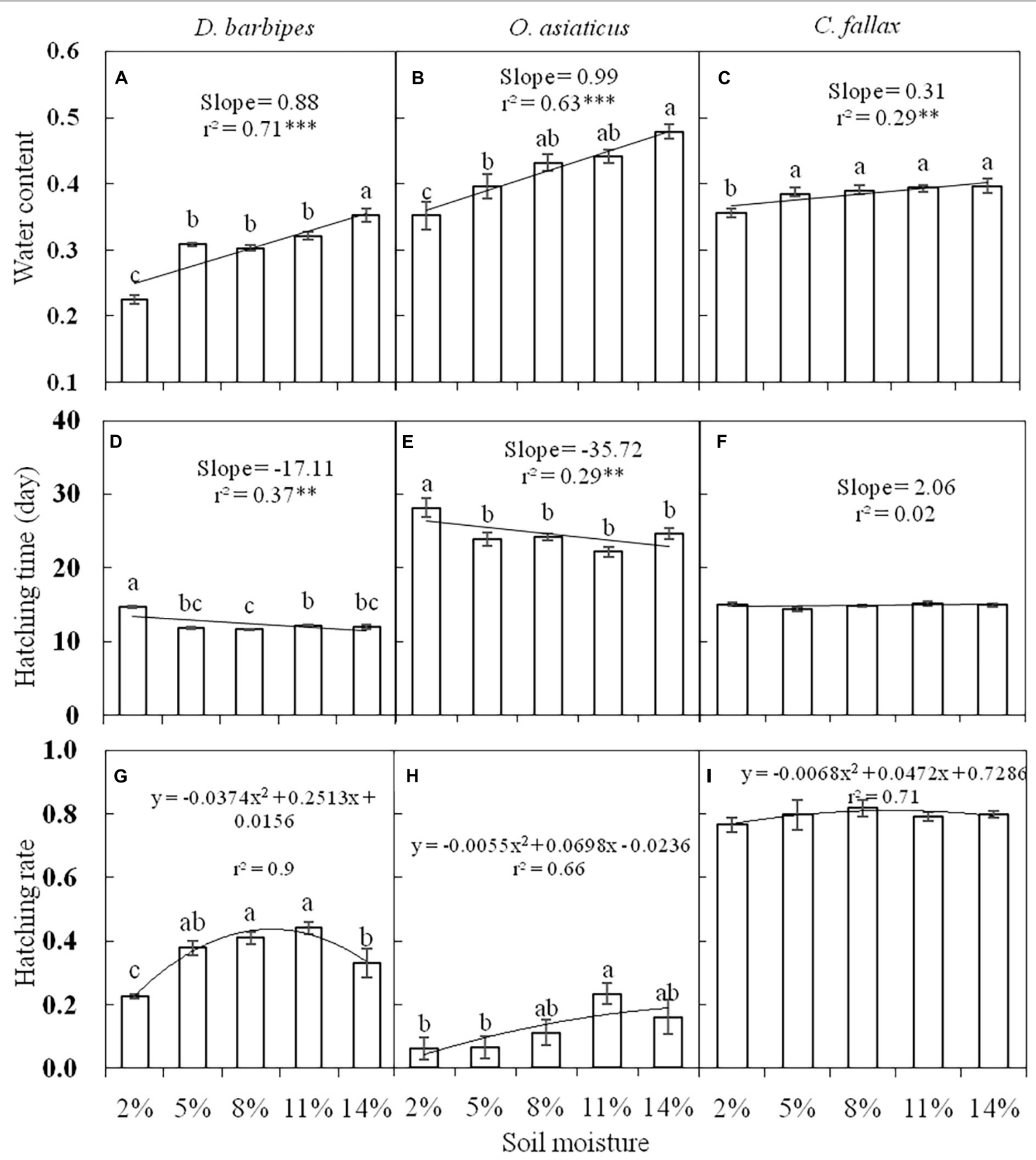

FIGURE 1 | The water content (A,B,C), hatching time (D,E,F), and hatching rate (G,H,I) of eggs of D. barbipes, O. asiaticus and C. fallax in different soil moisture treatments. Regression parameters were estimated using linear models with soil moisture as a continuous predictor. Significant regressions are indicated by $*(P<0.05),{ }^{* *}(P<0.01)$, and *** $(P<0.001)$. Lowercase letters above bars indicate within-species differences based on Tukey HSD post hoc analyses following ANOVA. Data are mean \pm SE $(n=6)$.

drought exposure duration $(P<0.01)$. There was no interactive effect of embryonic stage with drought exposure duration on the VI of hatching time of grasshopper eggs (Table 1).

There were significant interactive effects between drought exposure duration and grasshopper species on the hatching time of grasshopper eggs $\left[F_{(6,120)}=44.36, P<0.01\right]$. Drought exposure duration significantly increased the VI of hatching time of $D$. barbipes $\left.\left[F_{(3}, 40\right)=7.58, P<0.01\right]$, O. asiaticus $\left[F_{(3,40)}=4.25, P<0.05\right]$ and $C$. fallax $\left[F_{(3,40)}=52.76, P<0.01\right]$. The eggs of the three grasshopper species were sensitive to varied drought exposure durations. The VI of egg hatching time for C. fallax (0.87) was much larger than that of D. barbipes (0.03) and 
TABLE 1 | Results ( $F$ values) of two-way ANOVAs of the effect of soil temperature (ST) and soil moisture (SM), embryonic development stage, and drought exposure duration on the variation index $(\mathrm{VI})$ of hatching time and hatching rate of eggs of three grasshopper species.

\begin{tabular}{|c|c|c|c|c|c|c|c|}
\hline \multirow[t]{2}{*}{ Source } & \multirow[t]{2}{*}{$D f$} & \multicolumn{2}{|c|}{ D. barbipes } & \multicolumn{2}{|c|}{ O. asiaticus } & \multicolumn{2}{|c|}{ C. fallax } \\
\hline & & Hatching time & Hatching rate & Hatching time & Hatching rate & Hatching time & Hatching rate \\
\hline ST & 1 & $1378.53^{\mathrm{C}}$ & $36.94^{c}$ & $5.68^{a}$ & 0.60 & $344.93^{c}$ & 0.00 \\
\hline SM & 1 & $20.80^{b}$ & $10.48^{b}$ & $30.58^{c}$ & 1.68 & $4.47^{a}$ & 0.51 \\
\hline $\mathrm{ST} \times \mathrm{SM}$ & 1 & 2.53 & 0.32 & 0.69 & 0.02 & 1.46 & 0.94 \\
\hline Error & 20 & & & & & & \\
\hline Stage & 1 & 0.03 & 3.55 & $4.83^{\mathrm{a}}$ & 0.86 & 0.04 & $10.33^{c}$ \\
\hline Drought & 3 & $7.58^{b}$ & 2.27 & $4.25^{b}$ & 1.73 & $52.76^{c}$ & $8.70^{\mathrm{c}}$ \\
\hline Stage $\times$ Drought & 3 & 1.64 & 1.58 & 0.57 & 0.45 & 1.70 & 1.16 \\
\hline Error & 40 & & & & & & \\
\hline
\end{tabular}

$n=6$ (Each treatment was repeated 6 times). Superscript letters denote significant differences between treatments. ${ }^{a} P<0.05,{ }^{b} P<0.01,{ }^{c} P<0.001$.

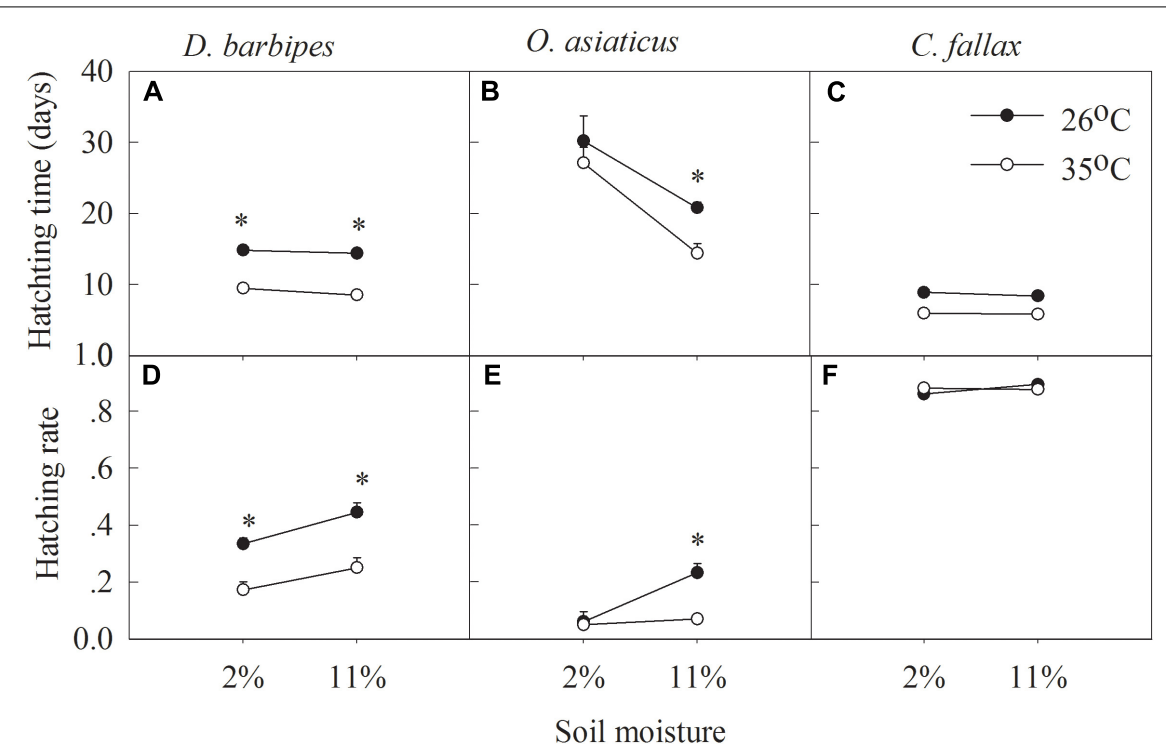

FIGURE 2 | Hatching time (A,B,C) and hatching rate (D,E,F) of eggs of $D$. barbipes, $\mathrm{O}$. asiaticus and $C$. fallax in different combined treatments of soil temperature and moisture. Data are mean \pm SE $(n=6)$. ${ }^{*}$ Indicates a significant difference between the two temperature treatments at the same soil moisture level at $P<0.05$.

O. asiaticus (0.07) $\left[F_{(2,120)}=519.86, P<0.01\right.$; Figures 3A-C]. Thus, the egg hatching time of $C$. fallax was the most sensitive to prolonged drought duration in the three grasshopper species. Regression analysis also showed that the VI of egg hatching time of D. barbipes and C. fallax was positively correlated with drought exposure duration at the two embryonic stages.

Averaged over the three grasshopper species, the embryonic stage had no effect on the VI of the hatching rate of grasshopper eggs. Drought exposure duration had a significant effect on the VI of the hatching rate of grasshopper eggs $\left[F_{(3,40)}=4.30\right.$, $P<0.01]$. Drought exposure duration significantly reduced the VI of the hatching rate of $C$. fallax but had no effect on that of $O$. asiaticus and D. barbipes (Table 1 and Figures 3D-F). There were no interactive effects of embryonic stage and drought exposure duration on the VI of the hatching rate of grasshopper eggs (Table 1).

There were interactive effects of embryonic stage and grasshopper species on the VI of the hatching rate of grasshopper eggs $\left[F_{(2,120)}=3.59 ; P<0.05\right]$. The VI of the hatching rate of $D$. barbipes eggs with prediapause development for 15 days was marginally significantly $\left[F_{(1,40)}=3.55 ; P=0.07\right]$ higher than that of eggs with prediapause development for 5 days. No differences existed in the VI of the hatching rate of $O$. asiaticus at 5 and 15 days of prediapause development. However, the VI of the hatching rate of C. fallax at 15 days of prediapause development was significantly lower than that at 5 days of prediapause development (Figures 3D-F).

The responses of egg hatching rate to drought exposure duration in the three grasshopper species varied. The VI of the egg hatching rate of $D$. barbipes was negatively correlated with drought exposure duration at the embryonic stage of prediapause development for 5 days. The VI of the egg hatching rate of $O$. asiaticus varied with drought exposure duration in the form of a binomial curve. The VI of the egg hatching rate of C. fallax was negatively correlated with drought exposure at the two embryonic stages. 

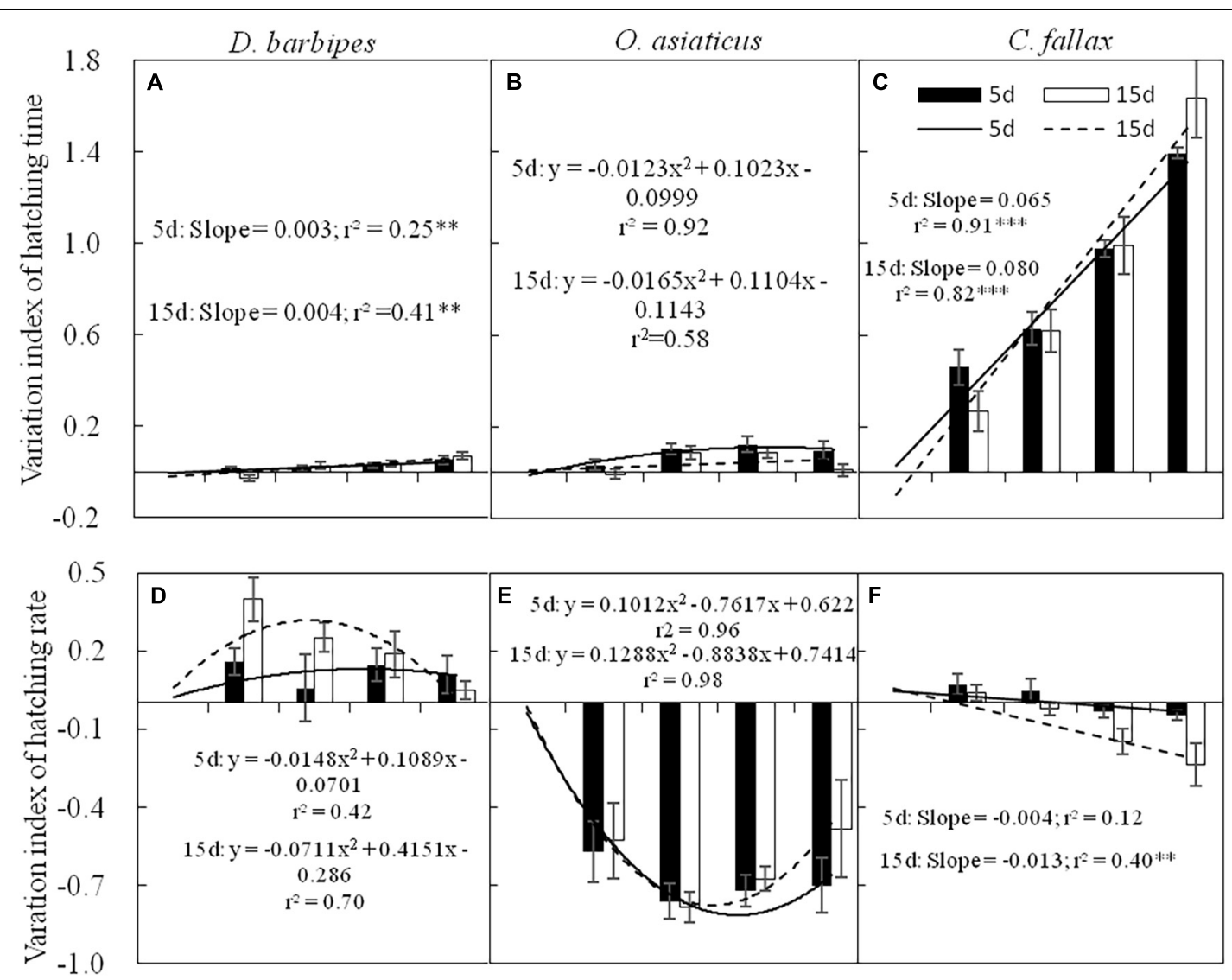

$\begin{array}{lllllllllllllll}0 \mathrm{~d} & 5 \mathrm{~d} & 10 \mathrm{~d} & 15 \mathrm{~d} & 20 \mathrm{~d} & 0 \mathrm{~d} & 5 \mathrm{~d} & 10 \mathrm{~d} & 15 \mathrm{~d} & 20 \mathrm{~d} & 0 \mathrm{~d} & 5 \mathrm{~d} & 10 \mathrm{~d} & 15 \mathrm{~d} & 20 \mathrm{~d}\end{array}$

Drought duration

FIGURE 3 | Variation index (VI) of hatching time (A,B,C) and hatching rate (D,E,F) of eggs of D. barbipes, O. asiaticus and C. fallax predeveloping for 5 and 15 days under different drought durations. $\mathrm{VI}=$ (treatment-control)/control. $\mathrm{VI}>0$ indicate an increase in the treatment compared with the control; $\mathrm{VI}=0$, means no change in the treatment compared with the control; and $<0$, indicates a decrease in the treatment compared with the control. Regression parameters were estimated using linear models with drought duration as a continuous predictor. Significant linear regressions are indicated by *(P<0.05), ${ }^{* *}(P<0.01)$, and $* * *(P<0.001)$. Data are mean $\pm \operatorname{SE}(n=6)$.

\section{DISCUSSION}

In this study, the water content, hatching time and hatching rate of eggs of three grasshopper species exhibited species-specific responses to variation in soil moisture and soil temperature. The embryonic development stages were highly sensitive to drought exposure duration. The response of the egg hatching rate to soil moisture clearly differed from that of egg hatching time and egg water content in the three grasshopper species. The distinct responses of grasshopper eggs reflect species-specific ecological traits associated with their phenology and habitat use (Stauffer et al., 2011).

\section{Grasshopper Species Show Distinct Responses to Soil Moisture Variation}

The egg water content of the three grasshopper species was positively correlated with changes in soil moisture, although the changes in soil moisture did not greatly affect the water content of C. fallax. The different responses of the eggs of the three grasshopper species to soil moisture may contribute to the different structures of egg pods. Egg pods of D. barbipes and C. fallax were generally wrapped by a compound of froth and sand, which can permit eggs to with stand dehydration or saturation under extreme soil conditions; the crust of the egg pod of C. fallax was harder and tighter than that of $O$. asiaticus and $D$. barbipes. Therefore, the egg water content of the egg pods of C. fallax was more stable in extremely dry or moist environments egg pods. The weak response of the egg water content of C. fallax to soil moisture also supports this observation. The linear responses of the egg water content of $O$. asiaticus to increasing soil moisture were similar to those of the migratory locust (Locusta migratoria) (Qi et al., 2007) because their egg pods both have weakened and spongy crust structures. Therefore, the higher sensitivity of $O$. asiaticus to soil moisture compared with $D$. barbipes and $C$. fallax suggested that the crust of the egg pods had a greater buffer capacity to changes in soil moisture. 
In addition, soil type, texture and $\mathrm{pH}$, which also affect the water uptake of grasshopper eggs from soil, are important for the embryonic development and survival of grasshopper eggs (Mukerji and Gage, 1978; Monk, 1985; Johnson and Worobec, 1988; Skinner and Child, 2000). Overall, based on the relationships between egg water content and soil moisture in our experiments, nearly $8 \%$ soil moisture is optimal for the egg development and survival of the three grasshopper species.

The different responses of egg hatching time and hatching rate of the three grasshopper species to soil moisture may be attributed to their distinct life history strategies. The egg water content, hatching time and hatching rate of $D$. barbipes and $O$. asiaticus were more sensitive to changes in soil moisture compared with C. fallax. In fact, D. barbipes and O. asiaticus occur in relatively dry habitats, whereas $C$. fallax occupies mesophilous environment with tall grass with higher soil moisture (Kang and Chen, 1994a,b). This indicates that grasshopper species occupying wet habitats are better adapted to higher soil moisture, whereas grasshopper species occupying dry habitats are better adapted to lower soil moisture. Although the egg hatching time and hatching rate of C. fallax were not affected by $5-14 \%$ soil moisture, they were delayed and reduced, respectively, under increased drought exposure duration. These results indicate that C. fallax was more sensitive to drought than to increases in soil moisture. Habitat, including vegetation structure, orientation of the sun, and the extent of shelter from wind, can greatly affect the adaptation of insects to environmental moisture (Wingerden et al., 1991; Stauffer et al., 2011). Thus, difference in the crust structure of the egg pods, habitat use and diapause traits can account for the distinct responses of the three grasshopper species to variation in soil temperature and soil moisture.

\section{Soil Temperature and Soil Moisture Were Important Factors Affecting the Development and Survival of Grasshopper Eggs}

Higher soil temperature shortened the hatching time of the three grasshopper species. Soil temperature in early spring and late autumn is close to the low threshold for grasshopper development, and warming in spring or autumn significantly facilitates the embryonic development of grasshopper eggs ( Wu et al., 2012). Another study indicated that soil moisture and temperature could account for $99 \%$ of the variance in egg hatching time (Mukerji and Gage, 1978; Powell et al., 2007). Moreover, higher soil temperature significantly reduced the egg hatching rate of early-season $D$. barbipes, indicating that $D$. barbipes is better adapted to lower soil temperatures. Soil temperature is thus an important environmental factor affecting the hatching and survival of grasshopper eggs, especially for early-season grasshopper species. Our data suggested that climate warming may affect the fitness and distribution of grasshoppers in temperate grasslands by altering their phenology and survival.

The hatching time of the three grasshopper species was prolonged at $2 \%$ soil moisture compared with $11 \%$ soil moisture. In addition, the reduced hatching rate of D. barbipes at $2 \%$ soil moisture indicated that soil moisture was another crucial environmental factor regulating the hatching time and survival of grasshopper eggs. Our results are consistent with the fact that soil moisture could explain $83 \%$ of the variance in egg mortality (Mukerji and Gage, 1978).

Although increased drought duration delayed the egg hatching time and reduced the egg hatching rate of the three grasshopper species, $2 \%$ soil moisture and 20 days drought exposure could not prevent egg hatching. Eggs of a tropical grasshopper species can hatch in soil moisture as low as $1 \%$ (Gehrken and Doumbia, 1996). Therefore, within a specific temperature and moisture spectrum, soil temperature may have greater effects than soil moisture on egg hatching time and hatching rate, especially for early-season grasshopper species.

There were no marked interactive effects of soil temperature and moisture on the egg hatching time and hatching rate of the three grasshopper species. This result is inconsistent with previous studies, in which warm and dry weather in spring have been shown to potentially favor the completion of embryonic development and hatching (Pickford, 1966). Warm and dry conditions in autumn or cool and wet conditions in spring are not favorable for grasshopper populations because these conditions reduce embryonic development and the survival of eggs (Powell et al., 2007). Indeed, some studies have shown that the mortality of locust eggs increases under long-term exposure to low temperature and high moisture (Qi et al., 2007). These studies indicate that the combined effects of temperature and moisture are seasonal or species-specific.

\section{Species-Specific Responses of Hatching Time and Hatching Rate at Different Embryonic Stages to Drought Exposure Duration}

The embryonic stages sensitive to environmental drought exposure varied among the different grasshopper species. Previous studies have reported that the inception of diapause is dependent on the temperature and moisture conditions at the time when eggs are laid (Wardhaugh, 1980). The diapause stage of grasshopper eggs is more tolerant of extreme soil drought conditions than the no-diapause stage (Gehrken and Doumbia, 1996; Bale et al., 2002). Therefore, diapause can buffer eggs from the negative effects of drought on embryonic development in $D$. barbipes and $O$. asiaticus, which enter diapauses early (stages 16-17) after developing for 15 days at normal temperature. Therefore, the egg hatching rates of D. barbipes and O. asiaticus after development for 15 days at normal temperature were not significantly affected by drought exposure duration. Our results indicated that the egg diapause of grasshoppers plays an important role in resisting environmental drought stress. Similarly, summer egg diapause in a matchstick grasshopper synchronizes the life cycle and buffers thermal extremes (Kearney et al., 2018).

The unchanged responses of eggs developing for 5 days at normal temperature of the three grasshopper species may be attributed to the early embryonic stage, as the physiological processes of grasshopper eggs may not yet be sensitive to soil moisture change. Grasshopper eggs require little water to 
develop before the anatrepsis stage (Pickford, 1966; Gehrken and Doumbia, 1996). The physiological sensitivity and biotic properties of grasshopper eggs in postdiapause development are important for estimating their biological response to climate change (Deutsch et al., 2008; Laws and Belovsky, 2010).

\section{CONCLUSION}

Although the development and survival of grasshopper eggs are regulated by complex environmental factors, our results suggested that soil temperature was the most important factor affecting the hatching time and hatching rate of grasshopper eggs in temperate grassland. The difference in habitat use, the crust structure of the egg pods, and diapause traits can account for the distinct responses of the three grasshopper species to variation in soil temperature and soil moisture. These findings enhance our ability to predict future changes in grasshopper populations and aid the sustainable control of temperate grasslands.

\section{DATA AVAILABILITY STATEMENT}

The original contributions presented in the study are included in the article/supplementary material,

\section{REFERENCES}

Allen, C. D., Macalady, A. K., Chenchouni, H., Bachelet, D., McDowell, N., Vennetier, M., et al. (2010). A global overview of drought and heat-induced tree mortality reveals emerging climate change risks for forests. For. Ecol. Manag. 259, 660-684. doi: 10.1016/j.foreco.2009.09.001

Bale, J. S., Masters, G. J., Hodkinson, I. D., Awmack, C., Bezemer, T. M., Brown, V. K., et al. (2002). Herbivory in global climate change research: direct effects of rising temperature on insect herbivores. Glob. Change Biol. 8, 1-16. doi: 10.1046/j.1365-2486.2002.00451.x

Briere, J. F., Pracros, P., Le Roux, A. Y., and Pierre, J. S. (1999). A novel rate model of temperature-dependent development for arthropods. Environ. Entomol. 28, 22-29. doi: 10.1093/ee/28.1.22

Coxwell, C., and Bock, C. (1995). Spatial variation in diurnal surface temperatures and the distribution and abundance of an alpine grasshopper. Oecologia 104, 433-439. doi: 10.1007/bf00341340

Deutsch, C., Tewksbury, J., Huey, R., Sheldon, K., Ghalambor, C., Haak, D., et al. (2008). Impacts of climate warming on terrestrial ectotherms across latitude. Proc. Natl. Acad. Sci. U.S.A. 105, 6668-6672. doi: 10.1073/pnas.07094 72105

Dingle, H., and Mousseau, T. (1994). Geographic variation in embryonic development time and stage of diapause in a grasshopper. Oecologia 97, 179185. doi: $10.1007 / \mathrm{bf00323147}$

Frampton, G. K., Brink, P. J. V. D., and Gould, P. J. L. (2000). Effects of spring drought and irrigation on farmland arthropods in Southern Britain. J. Appl. Ecol. 37, 865-883. doi: 10.1046/j.1365-2664.2000.00541.x

Gehrken, U., and Doumbia, Y. (1996). Diapause and quiescence in eggs of a tropical grasshopper Oedaleus senegalensis (Krauss). J. Insect Physiol. 42, 483-491. doi: 10.1016/0022-1910(95)00128-x

Gherlenda, A. N., Haigh, A. M., Moore, B. D., Johnson, S. N., and Riegler, M. (2016). Climate change, nutrition and immunity: effects of elevated CO2 and temperature on the immune function of an insect herbivore. J. Insect Physiol. 85, 57-64. doi: 10.1016/j.jinsphys.2015.12.002

Groeters, F., and Shaw, D. (1992). Association between latitudinal variation for embryonic development time and chromosome structure in the grasshopper Caledia captiva (Orthoptera: Acrididae). Evolution 46, 245-257. doi: 10.2307/ 2409819 further inquiries can be directed to the corresponding author/s.

\section{AUTHOR CONTRIBUTIONS}

All authors listed have made a substantial, direct and intellectual contribution to the work, and approved it for publication.

\section{FUNDING}

This study was funded by the National Natural Science Foundation of China (Grant No. 31572459), the Knowledge Innovation Program in the Chinese Academy of Sciences (Grant No. KSCX2-YW-Z-1021), and grants from the Public Welfare Fund for Agriculture (Project No: 2009 03021).

\section{ACKNOWLEDGMENTS}

We thank referees for providing comments that helped improve the manuscript.

Guo, K., Hao, S. G., Sun, O. J. X., and Kang, L. (2009). Differential responses to warming and increased precipitation among three contrasting grasshopper species. Glob. Change Biol. 15, 2539-2548. doi: 10.1111/j.1365-2486.2009. 01861.x

Hao, S. G., and Kang, L. (2004a). Effects of temperature on the post-diapause embryonic development and the hatching time in three grasshopper species (Orth., Acrididae). J. Appl. Entomol. 128, 95-101. doi: 10.1046/j.1439-0418. 2003.00810.x

Hao, S. G., and Kang, L. (2004b). Postdiapause development and hatching rate of three grasshopper species (Orthoptera: Acrididae) in Inner Mongolia. Environ. Entomol. 33, 1528-1534. doi: 10.1603/0046-225x-33.6.1528

Honek, A., and Kocourek, F. (1990). Temperature and development time in insects: a general relationship between thermal constants. Zool. Jahrb. Abt. Syst. Ökol. Geogr. Tiere 117, 401-439.

Jentsch, A., Kreyling, J., Boettcher-Treschkow, J., and Beierkuhnlein, C. (2009). Beyond gradual warming: extreme weather events alter flower phenology of European grassland and heath species. Glob. Change Biol. 15, 837-849. doi: 10.1111/j.1365-2486.2008.01690.x

Johnson, D., and Worobec, A. (1988). Spatial and temporal computer analysis of insects and weather: grasshoppers and rainfall in Alberta (Canada). Mem. Entomol. Soc. Can. 146, 33-48. doi: 10.4039/entm120146033-1

Kang, L., and Chen, Y. L. (1994a). Multidimensional analysis of resource utilization in assemblages of rangeland grasshoppers. Insect Sci. 1, 264-282. doi: 10.1111/ j.1744-7917.1994.tb00253.x

Kang, L., and Chen, Y. L. (1994b). Trophic niche of grasshoppers within steppe ecosystem in Inner Mongolia. Acta Entomol. Sin. 2, 178-189.

Kang, L., Han, X. G., Zhang, Z. B., and Sun, O. J. X. (2007). Grassland ecosystems in China: review of current knowledge and research advancement. Philos. Trans. R. Soc. B 362, 997-1008. doi: 10.1098/rstb.2007.2029

Katz, R., and Brown, B. (1992). Extreme events in a changing climate: variability is more important than averages. Clim. Change 21, 289-302. doi: 10.1007/ bf00139728

Kearney, M. R., Deutscher, J., Kong, J. D., and Hoffmann, A. A. (2018). Summer egg diapause in a matchstick grasshopper synchronises the life cycle and buffers thermal extremes. Integr. Zool. 13, 437-449. doi: 10.1111/1749-4877. 12314 
Laws, A., and Belovsky, G. (2010). How will species respond to climate change? Examining the effects of temperature and population density on an herbivorous insect. Environ. Entomol. 39, 312-319. doi: 10.1603/en09294

Masters, G. J., Brown,V. K., Clarke, I. P., Whittaker, J. B., and Holler, J. A. (1998). Direct and indirect effects of climate change on insect herbivores: Auchenorrhyncha (Homoptera). Ecol. Entomol. 23, 45-52. doi: 10.1046/j.13652311.1998.00109.x

Monk, K. (1985). Effect of habitat on the life history strategies of some British grasshoppers. J. Anim. Ecol. 54, 163-177. doi: 10.2307/4628

Mukerji, M., and Gage, S. (1978). A model for estimating hatch and mortality of grasshopper egg populations based on soil moisture and heat. Ann. Entomol. Soc. Am. 71, 183-190. doi: 10.1093/aesa/71.2.183

Parmesan, C. (2006). Ecological and evolutionary responses to recent climate change. Annu. Rev. Ecol. Evol. Syst. 37, 637-669. doi: 10.1146/annurev.ecolsys. 37.091305.110100

Parmesan, C., and Yohe, G. (2003). A globally coherent fingerprint of climate change impacts across natural systems. Nature 421, 37-42. doi: 10.1038/ nature 01286

Pickford, R. (1966). The influence of date of oviposition and climatic conditions on hatching of Camnula pellucida (Scudder)(Orthoptera: Acrididae). Can. Entomol. 98, 1145-1159. doi: 10.4039/ent9811 45-11

Poniatowski, D., Beckmann, C., Lffler, F., Münsch, T., Helbing, F., Samways, M. J., et al. (2020). Relative impacts of land-use and climate change on grasshopper range shifts have changed over time. Glob. Ecol. Biogeogr. 29, 2190-2202. doi: 10.1111/geb.13188

Powell, L. R., Berg, A. A., Johnson, D. L., and Warland, J. S. (2007). Relationships of pest grasshopper populations in Alberta, Canada to soil moisture and climate variables. Agric. For. Meteorol. 144, 73-84. doi: 10.1016/j.agrformet.2007.01. 013

Qi, X. L., Wang, X. H., Xu, H. F., and Kang, L. E. (2007). Influence of soil moisture on egg cold hardiness in the migratory locust Locusta migratoria (Orthoptera: Acridiidae). Physiol. Entomol. 32, 219-224. doi: 10.1111/j.1365-3032.2007. 00564.x

Root, T., Price, J., Hall, K., Schneider, S., Rosenzweig, C., and Pounds, J. (2003). Fingerprints of global warming on wild animals and plants. Nature 421, 57-60. doi: 10.1038/nature01333

Skinner, K., and Child, R. (2000). Multivariate analysis of the factors influencing changes in Colorado grasshopper abundances. J. Orthoptera Res. 23, 103-109. doi: $10.2307 / 3503640$

Srygley, R. B. (2014). Effects of temperature and moisture on Mormon cricket reproduction with implications for responses to climate change. J. Insect Physiol. 65, 57-62. doi: 10.1016/j.jinsphys.2014.05.005

Stauffer, T. W., Hatle, J. D., and Whitman, D. W. (2011). Divergent egg physiologies in two closely related grasshopper species: Taeniopoda eques versus Romalea microptera (Orthoptera: Romaleidae). Environ. Entomol. 40, 157-166. doi: 10. 1603/EN10200

Switanek, M., Crailsheim, K., Truhetz, H., and Brodschneider, R. (2016). Modelling seasonal effects of temperature and precipitation on honey bee winter mortality in a temperate climate. Sci. Total Environ. 579, 1581-1587. doi: 10.1016/j. scitotenv.2016.11.178
Telfer, M., and Hassall, M. (1999). Ecotypic differentiation in the grasshopper Chorthippus brunneus: life history varies in relation to climate. Oecologia 121, 245-254. doi: 10.1007/s004420050926

Wagner, T. L., Wu, H., Sharpe, P., Schoolfield, R. M., and Coulson, R. N. (1984). Modeling insect development rates: a literature review and application of a biophysical model. Ann. Entomol. Soc. Am. 77, 208-225. doi: 10.1093/aesa/77. 2.208

Walter, J. A., Ives, A. R., Tooker, J. F., and Johnson, D. M. (2018). Life history and habitat explain variation among insect pest populations subject to global change. Ecosphere 9:e02274.

Walther, G. R., Post, E., Convey, P., Menzel, A., Parmesan, C., Beebee, T. J. C., et al. (2002). Ecological responses to recent climate change. Nature 416, 389-395.

Wardhaugh, G. K. (1980). The effects of temperature and moisture on the inception of diapause in eggs of the Australian plague locust, Chortoicetes terminifera Walker (Orthoptera: Acrididae). Austral Ecol. 5, 187-191. doi: 10.1111/j.14429993.1980.tb01241.x

Wingerden, W., Musters, J., and Maaskamp, F. (1991). The influence of temperature on the duration of egg development in West European grasshoppers (Orthoptera: Acrididae). Oecologia 87, 417-423. doi: 10.1007/ BF00634600

Wu, T., Hao, S., Sun, O. J., and Kang, L. (2012). Specificity responses of grasshoppers in temperate grasslands to diel asymmetric warming. PLoS One 7:e41764. doi: 10.1371/journal.pone.0041764

Xi, X., Li, D., Peng, Y., Eisenhauer, N., and Sun, S. (2016). Experimental warming and precipitation interactively modulate the mortality rate and timing of spring emergence of a gallmaking Tephritid fly. Sci. Rep. 6:32284.

Yu, G., Shen, H., and Liu, J. (2009). Impacts of climate change on historical locust outbreaks in China. J. Geophys. Res. 114:D18104.

Zhang, Z., Cazelles, B., Tian, H., Stige, L., Bräuning, A., and Stenseth, N. (2009). Periodic temperature-associated drought/flood drives locust plagues in China. Proc. R. Soc. B Biol. Sci. 276, 823-831. doi: 10.1098/rspb.2008.1284

Zhao, Y. X., Hao, S. G., and Kang, L. (2005). Variations in the embryonic stages of overwintering eggs of eight grasshopper species (Orthoptera: Acrididae) in Inner Mongolian grasslands. Zool. Stud. 44, 536-542.

Conflict of Interest: The authors declare that the research was conducted in the absence of any commercial or financial relationships that could be construed as a potential conflict of interest.

Publisher's Note: All claims expressed in this article are solely those of the authors and do not necessarily represent those of their affiliated organizations, or those of the publisher, the editors and the reviewers. Any product that may be evaluated in this article, or claim that may be made by its manufacturer, is not guaranteed or endorsed by the publisher.

Copyright (c) $2021 \mathrm{Wu}$, Hao and Kang. This is an open-access article distributed under the terms of the Creative Commons Attribution License (CC BY). The use, distribution or reproduction in other forums is permitted, provided the original author(s) and the copyright owner(s) are credited and that the original publication in this journal is cited, in accordance with accepted academic practice. No use, distribution or reproduction is permitted which does not comply with these terms. 